OESOPHAGUS

\title{
Relationship between motor function of the proximal stomach and transient lower oesophageal sphincter relaxation after morphine
}

\author{
R Penagini, M Allocca, P Cantù, M Mangano, D Savojardo, S Carmagnola, P A Bianchi
}

Gut 2004;53:1227-1231. doi: 10.1136/gut.2003.035246

Background: Morphine reduces the rate of transient lower oesophageal sphincter (LOS) relaxations but its site of action is presently unknown. There are no data available concerning its motor effects on the proximal stomach, an important site for triggering transient LOS relaxations.

Aim: To evaluate the effect of morphine on the rate of transient LOS relaxations and motor function of the proximal stomach.

See end of article for authors' affiliations

(a)

Correspondence to: Professor R Penagini, IRCCS Ospedale

Maggiore, Pad Granelli,

Via F Sforza 35, 20122

Milano, Italy; bobpenna@

policlinico.mi.it

Revised version received 20 February 2004

Accepted for publication 3 March 2004
Subjects and methods: In 19 healthy subjects, concurrent transient LOS relaxations with a sleeve sensor and motor function of the proximal stomach with a bag connected to an electronic barostat were recorded during pressure controlled $(n=9)$ and volume controlled $(n=10)$ gastric distensions after intravenous administration of placebo and morphine $100 \mu \mathrm{g} / \mathrm{kg}$.

Results: During pressure controlled distensions, intrabag volume was markedly decreased by morphine (median $189 \mathrm{ml}$ (interquartile range 101-448) v 404 (265-868) after placebo; $\mathrm{p}<0.01$ ) as was the rate of transient LOS relaxations $(0.5 / 30$ minutes $(0.4-2)$ v $2.5(2-4) ; p<0.01)$. When intrabag volume was kept constant (525 $\mathrm{ml}$ (490-600)) (that is, in volume controlled distensions), the rate of transient LOS relaxations was not affected by morphine (2/30 minutes (2-3) v 2.5 (2-3)). Gastric contractions decreased after morphine similarly during pressure controlled and volume controlled distensions (8.5/ 30 minutes (4-10) v 15.5 (9.5-20.5), $\mathrm{p}<0.02$; and $6.5(0-24)$ v $19.5(12-22), \mathrm{p}<0.05)$.

Conclusions: The effect of morphine on transient LOS relaxations is dependent on the decrease in volume of the proximal stomach. Our data suggest that pharmacological interventions which decrease fundal volume should result in control of transient LOS relaxation mediated gastro-oesophageal reflux.
T ansient lower oesophageal sphincter (LOS) relaxation is the main motor event underlying gastro-oesophageal reflux in most patients with gastro-oesophageal reflux disease..$^{1-3}$ There is therefore an interest in developing drugs that decrease gastro-oesophageal reflux by interfering with transient LOS relaxation. ${ }^{4-8}$ Because stimulation of mechanoreceptors in the gastric fundus induced by gastric distension, as occurs after meals, is of major importance for triggering transient LOS relaxations, ${ }^{910}$ one possible drug mechanism of action is to alter fundal motor function in a way that would decrease mechanoreceptor stimulation. ${ }^{11}$

We have recently shown that morphine reduces the rate of transient LOS relaxations by stimulating $\mu$ opioid receptors, ${ }^{5}$ although the site of action is still unknown. On the one hand, opioid receptors are widespread along the afferent sensory pathways, as well as in various areas of the brain, enteric nervous system, and smooth muscle cells in the gut, ${ }^{12}{ }^{13}$ and on the other hand, morphine exerts profound effects on gastrointestinal motility but there are no data available concerning the proximal stomach. The drug could therefore affect transient LOS relaxation by modulating neural control pathways or by changing the motor activity of the proximal stomach.

The aim of the present study was to evaluate the effect of morphine on the rate of transient LOS relaxations and motor function of the proximal stomach during pressure controlled and volume controlled gastric distension studies.

\section{METHODS}

Study group

We studied 19 healthy subjects, aged 21-32 years (eight men) who had no symptoms or past history of gastrointestinal disease.
The study was approved by the Human Research Review Committee of the Ospedale Maggiore of Milan.

\section{Manometric and barostat measurements}

Oesophageal manometry was performed using a multilumen assembly which incorporated a $6 \mathrm{~cm}$ long sleeve sensor to monitor LOS pressure. ${ }^{5}$ Side holes recorded pressure in the gastric fundus and at levels 3,8 , and $13 \mathrm{~cm}$ above the LOS. A side hole in the pharynx monitored swallowing. The assembly was perfused with degassed distilled water by means of a low compliance pneumohydraulic infusion pump. The gastric side hole and sleeve were perfused at $0.5 \mathrm{ml} / \mathrm{min}$, and the side holes in the oesophageal body and pharynx at $0.13 \mathrm{ml} / \mathrm{min}$ in order to minimise the fluid load to the subject. Proximal gastric motor function was measured with an electronic barostat (Synectics Medical, Sweden) connected to a polyethylene bag with a capacity of approximately $1400 \mathrm{ml}$ via an assembly comprising a $2.5 \mathrm{~mm}$ internal diameter (ID) tube (to introduce or withdraw air from the bag) and a $0.97 \mathrm{~mm}$ ID tube (to sense pressure in the bag). Two further manometric lumina incorporated into the assembly had sideholes positioned 25 and $50 \mathrm{~mm}$ proximal to the top of the barostat bag which allowed reliable positioning of the bag within the stomach by detection of the characteristic patterns of pressure at the level of the diaphragm. These lumina were perfused with degassed distilled water. In pressure controlled distensions, pressure in the bag was maintained constant by introducing or withdrawing air at a rate of $30 \mathrm{ml} / \mathrm{s}$ whenever the pressure

Abbreviations: LOS, lower oesophageal sphincter; ID, internal diameter 
inside the bag differed from the set pressure by more than $0.4 \mathrm{~mm} \mathrm{Hg}$. Data from the pressure recording system (Synectics Medical) and the barostat were digitised and recorded on computer for online display and subsequent analysis.

\section{Study design}

Pressure controlled distensions were performed first in order to evaluate the effect of morphine on the proximal stomach. As a marked decrease in volume was observed during these experiments, a fixed volume balloon was used (volume controlled distensions) in order to assess the relationship between changes in gastric volume and in the transient LOS relaxation rate after morphine.

\section{Pressure controlled distensions}

Nine subjects were studied twice (placebo and morphine experiments) in a randomised order on separate occasions at least four days apart after an overnight fast (fig 1A). On each occasion the barostat assembly, with the bag folded around it, was introduced orally and positioned inside the stomach on the basis of the manometric recording. The bag was then unfolded by inflation with $500 \mathrm{ml}$ of air while ensuring that the pressure in the bag did not exceed $20 \mathrm{~mm} \mathrm{Hg}$. The bag was then deflated and the position of the assembly adjusted to its final position so that the point of respiratory reversal lay between the manometric sideholes, thereby positioning the proximal portion of the bag just below the diaphragm. The manometric assembly was introduced into the oesophagus through an anaesthetised nostril, the sleeve sensor being positioned straddling the LOS. Both assemblies were then fixed in position by taping them to the nose. Subjects sat upright on a comfortable stool in a standardised position so as not to compress the abdomen. After intubation and a 10 minute adaptation period, the intragastric bag was inflated by stepwise $2 \mathrm{~mm} \mathrm{Hg}$ increments every two minutes until the discomfort threshold was reached. The bag was then deflated completely and intrabag pressure was set at $75 \%$ of the previously determined discomfort threshold pressure and maintained for the 90 minutes of the experiment, comprising three sequential periods: 15 minute basal period; 60 minutes after intravenous administration of placebo or morphine $100 \mu \mathrm{g} / \mathrm{kg}$; and 15 minutes after intravenous administration of naloxone $40 \mu \mathrm{g} / \mathrm{kg}$. Injection of naloxone was carried out in the last seven subjects only.

\section{Volume controlled distensions}

Ten subjects were studied once, according to a previously validated protocol. ${ }^{14}$ Intubation and positioning of the assemblies were the same as those for the pressure controlled experiments. After intubation and a 10 minute adaptation period (fig $1 \mathrm{~B}$ ), the intragastric bag was inflated by stepwise $100 \mathrm{ml}$ increments every two minutes until the discomfort threshold was reached. The bag was then deflated completely and reinflated at a volume corresponding to $75 \%$ of the previously determined discomfort threshold volume which was maintained for two 35 minute distension periods, separated by a 45 minute washout period with the bag deflated. At the beginning of the first distension, a $1 \mathrm{ml}$ bolus of saline was injected intravenously whereas at the beginning of the second distension, morphine $100 \mu \mathrm{g} / \mathrm{kg}$ was administered. After a five minute period to allow for drug distribution, pressure recordings started and were carried out for the remaining 30 minute distension periods (placebo and morphine). Subjects remained awake during all experiments.

\section{Data analysis \\ Transient LOS relaxation}

As previously described, ${ }^{15}$ transient LOS relaxation was defined by the following criteria: (1) absence of swallowing from four seconds before to two seconds after the onset of LOS relaxation; (2) relaxation rate of $\geqslant 1 \mathrm{~mm} \mathrm{Hg} / \mathrm{s}$; (3) time from the onset of relaxation to complete relaxation of $\leqslant 10$ seconds; and (4) nadir pressure of $\leqslant 2 \mathrm{~mm} \mathrm{Hg}$. The rate of transient LOS relaxations was expressed as number/ 30 minutes.

\section{Pressure controlled distensions: intrabag volume and volume waves}

Intrabag volume, as a measure of proximal gastric tone, was calculated as the mean value of each five minute interval, excluding variations due to volume waves, and expressed as the mean value every 15 minutes. Volume waves were evaluated as a measure of gastric contractions and, in accordance with previous criteria, ${ }^{16}$ were defined as a change in volume of more than $30 \mathrm{ml}$ that reverted to a volume within $50 \%$ of the previous level in less than two minutes. The rate of volume waves was expressed as number/ 30 minutes.

\section{Volume controlled distensions: intrabag pressure and pressure waves}

Similarly to intrabag volume in the pressure controlled distensions, intrabag pressure, as a measure of proximal gastric tone, was calculated as the mean value of each five minute interval, excluding variations due to pressure waves, and expressed as the mean value every 15 minutes. Pressure waves (that is, gastric contractions) were defined as changes in pressure of $\geqslant 3 \mathrm{~mm} \mathrm{Hg}$ above intrabag pressure which were not associated with abdominal strain. Amplitude of pressure waves was measured with reference to intrabag pressure. The rate of pressure waves was expressed as number/30 minutes.

\section{Statistical analysis}

Results are expressed as median (interquartile range) or mean (SEM) values according to data distribution. Similarly,
A Discomfort

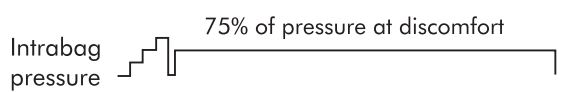

Time (min)

IV

injections

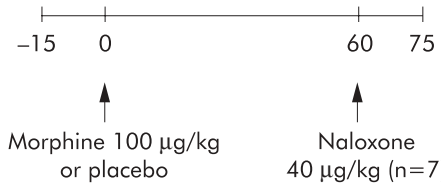

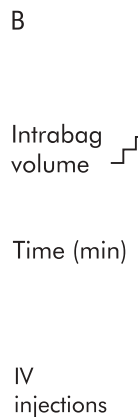

B

injections
Discomfort

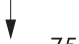

$75 \%$ of volume

at discomfort at discomfort

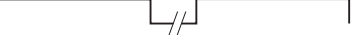

Recording period Recording period
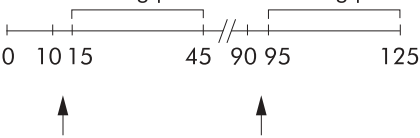

Placebo

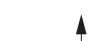

Morphine

$100 \mu \mathrm{g} / \mathrm{kg}$
Figure 1 Design of the pressure controlled (A) and volume controlled (B) distensions. 
Table 1 Transient lower oesophageal sphincter (LOS) relaxations and motor function of the proximal stomach in the basal period during pressure controlled distensions

\begin{tabular}{lcc}
\hline & $\begin{array}{l}\text { Placebo } \\
\text { experiment }\end{array}$ & $\begin{array}{l}\text { Morphine } \\
\text { experiment }\end{array}$ \\
\hline Transient LOS relaxations & $2(1-3)$ & $2(1-2)$ \\
(No/15 min) & $496(371-859)$ & $561(229-888)$ \\
Intrabag volume $(\mathrm{ml})^{*}$ & $7(1-8)$ & $6(3-11)$ \\
Volume waves (No $/ 15 \mathrm{~min})$ & \begin{tabular}{l}
7 \\
\hline
\end{tabular}
\end{tabular}

Values are median (interquartile range)

*As a measure of proximal gastric tone.

the statistical significance of differences between placebo and morphine was tested by the Wilcoxon test or the Student's $t$ test. Statistical significance of differences among intrabag volumes during each experiment of pressure controlled distensions was tested by non-parametric analysis of variance followed by the Neuman-Keuls test for multiple comparisons.

\section{RESULTS}

\section{Pressure controlled distensions}

Intrabag pressure during the placebo and morphine experiments was 10.8 (1.1) $\mathrm{mm} \mathrm{Hg}$.

As shown in table 1, the rate of transient LOS relaxations, intrabag volume, and the rate of volume waves during the basal period were similar on the two study days.

In contrast, all subjects had a markedly lower rate of transient LOS relaxations after morphine than after placebo (median 0.5/30 minutes (interquartile range 0.4-2) $v 2.5$ $(2-4) ; \mathrm{p}<0.01$ ) (fig 2A). Similarly, all subjects had a smaller intrabag volume (that is, higher gastric tone) after morphine compared with placebo (189 ml (101-448) v 404 (265-868); $\mathrm{p}<0.01$ ) (fig 3 ). The rate of volume waves was also markedly lower after morphine (8.5/30 minutes (4-10) v 15.5 (9.5$20.5) ; \mathrm{p}<0.02)$. The motor effects of morphine on the proximal stomach can be clearly seen in the representative barostat tracing shown in fig 4.

Analysis of the time course of intrabag volumes in seven subjects who received naloxone at the end of the experiment (fig 5) showed that volume remained stable throughout the placebo experiment whereas it decreased markedly after morphine and reverted to basal values after naloxone injection in the morphine experiment.

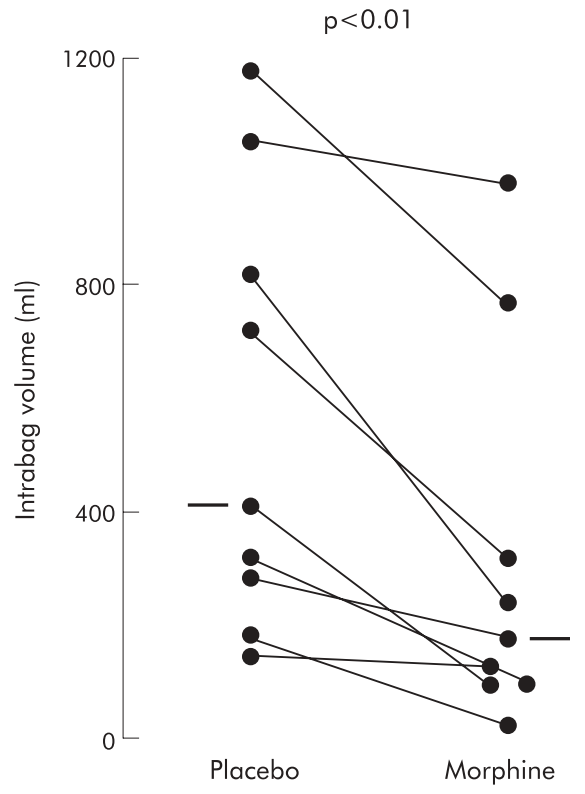

Figure 3 Pressure controlled distensions. Intrabag volume after placebo and morphine. Horizontal bars indicate median values.

\section{Volume controlled distensions}

Intrabag volume during placebo and morphine was $525 \mathrm{ml}$ (490-600). Unlike pressure controlled distensions, the rate of transient LOS relaxations did not decrease after morphine (fig 2B): 2/30 minutes (2-3) versus 2.5 (2-3). Intrabag pressure increased in seven of 10 subjects after morphine but the change did not reach statistical significance (11.2 mmHg (9.8-14.6) v $12.0(10.0-13.1))$. As in the case of pressure controlled distensions, the rate of pressure waves was markedly lower after morphine compared with placebo (6.5/30 minutes (0-24) v 19.5 (12-22); $\mathrm{p}<0.05)$.

\section{Mental state}

After morphine, all subjects felt a sensation of well being and peacefulness that lasted throughout the experimental period and was promptly reverted by naloxone $(n=7)$. Two subjects in the pressure controlled experiments and three in the

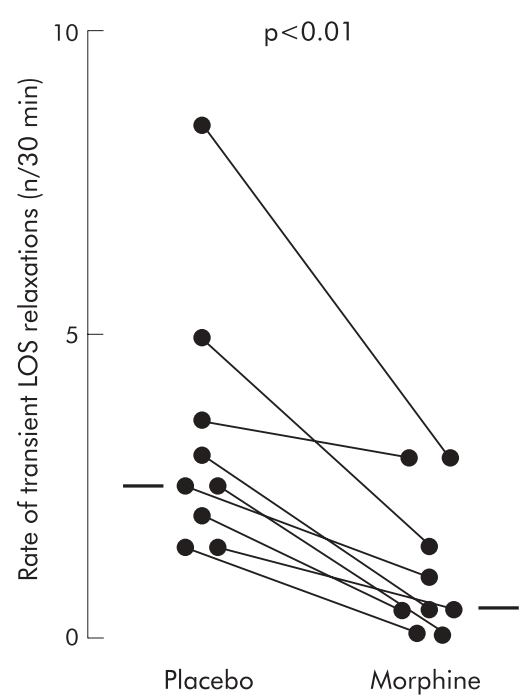

B

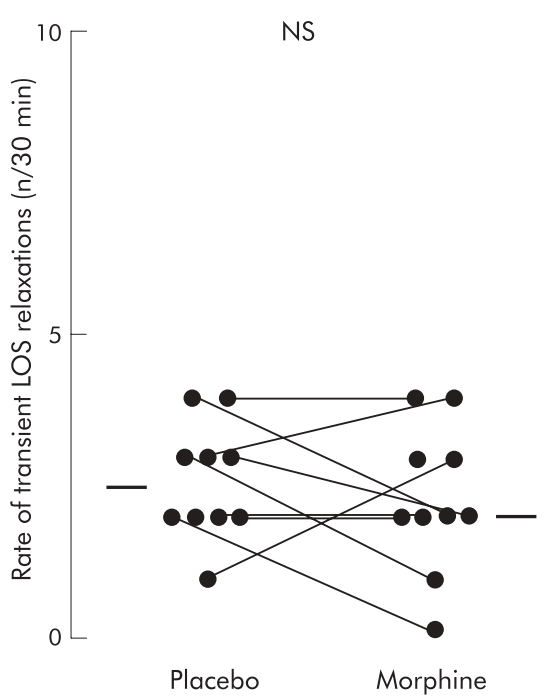

Figure 2 Rate of transient lower oesophageal sphincter (LOS) relaxations after placebo and morphine during pressure controlled $(\mathrm{A})$ and volume controlled (B) distensions. Horizontal bars indicate median values. 


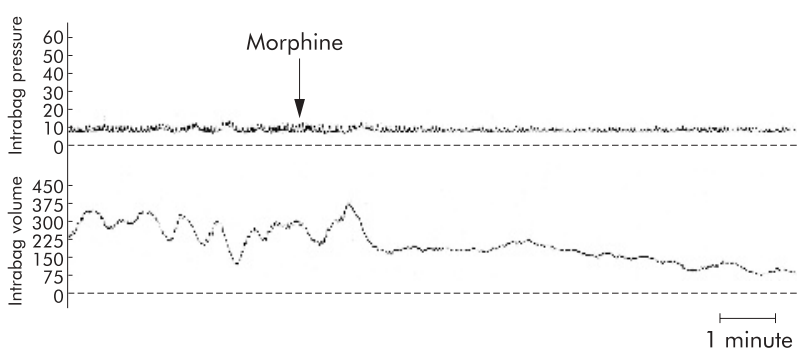

Figure 4 Barostat tracing during a pressure controlled distension from one subject at the time of morphine administration. Note the marked and stable decrease in intrabag volume and rate of volume waves within 90 seconds of morphine administration. Pressure is expressed in $\mathrm{mm} \mathrm{Hg}$ and volume in $\mathrm{ml}$.

volume controlled experiments also experienced drowsiness. All subjects remained awake throughout the experiments.

\section{DISCUSSION}

The first part of this study (that is, pressure controlled distensions) confirmed the effect of morphine on the rate of transient LOS relaxations, ${ }^{5}$ and showed that the drug also profoundly affects the motor function of the proximal stomach. Reversal of both effects by naloxone strongly suggests that they are mediated by $\mu$ receptors. ${ }^{17}{ }^{18}$ The decrease in the rate of transient LOS relaxations and volume of the proximal stomach allowed us to use morphine in the second part of this study as a model to investigate the relationship between volume of the gastric fundus and triggering of transient LOS relaxation by means of volume controlled distensions. The results showed that when the decrease in fundal volume was blocked, the effect of morphine on transient LOS relaxations was no longer seen, indicating that the latter was dependent on the decrease in the former.

As morphine has a half life of three hours, ${ }^{19}$ it was always administered second in the volume controlled studies in order to avoid a carryover effect. Although it may be argued that this may have introduced an order effect, we are confident that this was not the case because our previous validation of the experimental model showed that the rate of transient LOS relaxations and motor function of the proximal stomach are similar during the two distensions when no drugs are administered. ${ }^{14}$

Morphine had two apparently contradictory motor effects on the proximal stomach: it increased tone (as shown by the marked decrease in volume during pressure controlled distensions) and it concurrently decreased the rate of gastric contractions. The motor effects of morphine, and of opioid agonists in general, are quite complex and depend on the animal species, dose, and segment of the gastrointestinal tract investigated; various reports have described opposite effects on tone and either contractions or propulsion. ${ }^{20}$

It is interesting to note that whereas morphine decreased gastric contractions similarly in the pressure controlled and volume controlled experiments, no significant increase in tone was seen during the latter. This may depend on both neurophysiological and technical reasons which may require a larger number of subjects in order to detect a difference. Firstly, during the volume controlled experiments, variations in tone, as measured by changes in pressure, were much smaller than changes in volume measured during the pressure controlled distensions, probably because a tonic contraction against a fixed volume activates reflexes to prevent a pressure rise, as has been previously described during graded volume controlled distensions of the proximal stomach in which a non-linear pressure rise occurring at

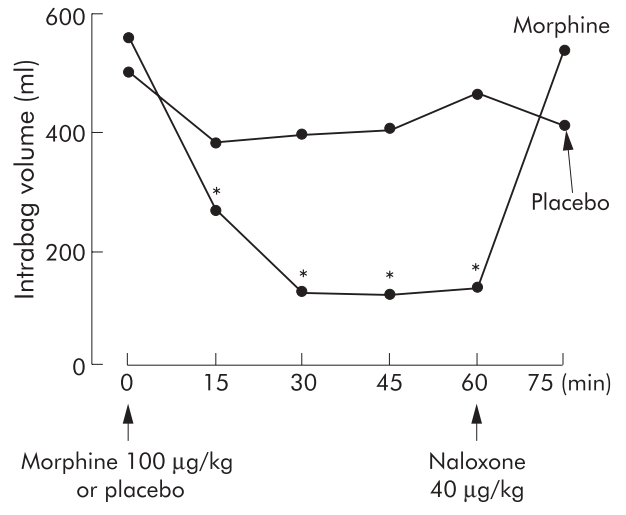

Figure 5 Pressure controlled distensions. Median 15 minute intrabag volume during placebo and morphine $(n=7)$. ${ }^{*} p<0.05$ versus basal.

lower volumes is followed by a plateau phase at higher volumes. ${ }^{21}$ Secondly, as tone is assessed in periods between gastric contractions, their different rate between placebo and morphine distensions may have introduced a technical bias by allowing a different amount of time available for analysis.

How did the effect of morphine on the proximal stomach affect transient LOS relaxations? Previous animal studies have suggested that both stretch and tension mechanoreceptors are present in the stomach..$^{22-25}$ The former are thought to be in parallel with smooth muscle fibres and sensitive to elongation and the latter in series and sensitive to contraction and elongation. Although controversy still exists, ${ }^{26-28}$ stretch receptors seem to be more relevant than tension receptors in triggering transient LOS relaxation ${ }^{29}$ and the present data support this evidence, as discussed below. In our pressure controlled studies, during which morphine decreased the rate of transient LOS relaxations, morphine decreased stimulation of stretch receptors by decreasing fundal volume and probably also decreased stimulation of tension receptors. On the one hand, the rate of contractions (that stimulate tension mechanoreceptor discharge) ${ }^{23}{ }^{24}$ was decreased after the drug but on the other hand, according to Laplace's law, a smaller radius with the same intragastric pressure reduces wall tension and consequently tensoreceptor stimulation. In the volume controlled studies, in which morphine did not affect the rate of transient LOS relaxations, stimulation of stretch receptors was unchanged whereas tension receptors were presumably still stimulated less because of the decrease in contraction rate. In brief, our data suggest that morphine decreased the rate of transient LOS relaxations mainly by decreasing stimulation of the fundal mechanoreceptors sensitive to stretch.

Was the action of morphine on the fundus and transient LOS relaxation peripheral or did it take place at the level of the central nervous system? Our experiments do not allow us to answer this question. In addition to being in the stomach, ${ }^{12}$ opioid receptors are also located in areas in the brain that control afferent and efferent pathways, ${ }^{13}$ and so morphine may affect the motility of the proximal stomach by acting at the level of the central nervous system, as has previously been shown for intestinal motility. ${ }^{30}{ }^{31}$ The finding that loperamide, a peripheral opioid agonist, does not affect gastrooesophageal reflux in patients with endoscopy negative reflux disease ${ }^{32}$ indirectly suggests that $\mu$ opioid receptor stimulation at the periphery has no effect on transient LOS relaxation.

Finally, what is the relevance of our experiments in relation to the postprandial period and, in particular, would morphine have shown the same decrease in gastric volume and transient LOS relaxations after a meal? We cannot 
answer this question. However, previously published data allow us to hypothesise that the postprandial effect could be similar. To the best of our knowledge, only intravenous erythromycin has been shown to induce a marked decrease in volume during fasting pressure controlled distensions, ${ }^{33}$ similar to that induced by morphine; when experiments were performed after a meal, marked shortening of postprandial relaxation was seen. ${ }^{34}$ Furthermore, three drugs that decrease the rate of transient LOS relaxations during gas or balloon distension of the proximal stomach (that is, atropine, loxiglumide, and L-NMMA) have shown a similar effect when tested after a meal, regardless of the site of action, which is still incompletely understood. ${ }^{6} 7$ 35-37

In conclusion, our data show that stimulation of $\mu$ opioid receptors induced by morphine decreases the rate of transient LOS relaxations and that this effect is mediated by a decrease in volume of the proximal stomach. The potential implication of our study is that pharmacological interventions that decrease fundal volume should result in control of transient LOS relaxation mediated gastro-oesophageal reflux.

\section{ACKNOWLEDGEMENTS}

This study was supported by a grant from the Associazione Amici della Gastroenterologia del Padiglione Granelli

\section{Authors' affiliations \\ R Penagini, M Allocca, P Cantù, M Mangano, D Savojardo,}

S Carmagnola, P A Bianchi, Cattedra di Gastroenterologia,

Dipartimento di Scienze Mediche, University of Milan-IRCCS Ospedale Maggiore, Milan, Italy

\section{REFERENCES}

1 Dodds W, Dent W, Hogan W, et al. Mechanisms of gastroesophageal reflux in patients with reflux esophagitis. N Engl J Med 1982;307:1547-52.

2 Mittal R, Holloway R, Penagini R, et al. Transient lower esophageal sphincter relaxation. Gastroenterology 1995;109:601-10.

3 Penagini $\mathbf{R}$, Schoeman $M$, Tippett $M$, et al. Motor event underlying gastroesophageal reflux in ambulant patients with reflux oesophagitis. Neurogastroenterol Mot 1996;8:131-41.

4 Mittal RK, Holloway RH. Effect of atropine on the frequency of reflux and transient lower esophageal sphincter relaxation in normal subjects. Gastroenterology 1995; 109:1547-54

5 Penagini R, Bianchi P. Effect of morphine on gastroesophageal reflux and transient lower esophageal sphincter relaxation. Gastroenterology 1997; 113:409-14.

6 Boulant J, Mathieu S, D'Amato M, et al. Cholecystokinin in transient lower oesophageal sphincter relaxation due to gastric distension in humans. Gut 1997;40:575-81.

7 Hirsch DP, Holloway RH, Tytgat GNJ, et al. Involvement of nitric oxide in human transient lower esophageal sphincter relaxations and esophageal primary peristalsis. Gastroenterology 1998;115:1374-80.

8 Lidums I, Lehmann A, Checklin H, et al. Control of transient lower esophageal sphincter relaxations and reflux by the GABA agonist baclofen in normal subjects. Gastroenterology 2000;1 18:7-13.

9 Franzi S, Martin C, Cox M, et al. Response of canine lower esophageal sphincter to gastric distension. Am J Physiol 1990;259:G380-5.

10 Holloway RH, Kocyan P, Dent J. Provocation of transient lower esophageal sphincter relaxations by meals in patients with symptomatic gastroesophageal reflux. Dig Dis Sci 1991;36:1034-9.
11 Tack J Sifrim D. A little rest and relaxation. Gut 2000:47:11-12.

12 Bitar K, Makhlouf G. Receptors on smooth muscle cells: characterization by contraction and specific antagonists. Am J Physiol 1982;242:G400-7.

13 Mansour A, Fox C, Akil $\mathrm{H}$, et al. Opioid-receptor mRNA expression in the rat CNS: anatomical and functional implications. Trends Neurosci 1995; 18:22-9.

14 Carmagnola $S$, Cantù $P$, Savojardo $D$, et al. An experimental model for the study of transient lower oesophageal sphincter relaxation and motor function of the proximal stomach in humans. Neurogastroenterol Motil 2004; 16:287-92

15 Holloway R, Penagini R, Ireland A. Criteria for objective definition of transient lower esophageal sphincter relaxation. Am J Physiol 1995;268:G128-33.

16 Azpiroz F, Malagelada J. Physiological variations in canine gastric tone measured by an electronic barostat. Am J Physiol 1985;248:G229-37.

17 Sawynok J, Pinskj C, La Bella FS. Mini review on the specificity of naloxone as an opiate antagonist. Life Sci 1979;25:1621-32.

18 Paterson SJ, Robson LE, Kosterlitz HW. Classification of opioid receptors. $\mathrm{Br}$ Med Bull 1983;39:31-6.

19 Jaffe JH, Martin WR. Opioid analgesics and antagonists. In: Goodman Gilman A, Goodman LS, Gilman A, eds. The pharmacological basis of therapeutics. New York: Macmillan Publishing Co, Inc., 1980:494-534.

20 Kromer W. Endogenous and exogenous opioids in the control of gastrointestinal motility and secretion. Pharmacol Rev 1988;40:121-62.

21 Ahluwalia NK, Thompson DG, Barlow J, et al. Relaxation responses of the human proximal stomach to distension during fasting and after food. Am J Physiol 1994;267:G166-72.

22 Paintal A. Study of gastric stretch receptors. Their role in the peripheral mechanism of satiation of hunger and thirst. J Physiol 1954;126:255-70.

23 Iggo A. Tension receptors in the stomach and the urinary bladder. J Physiol 1955; 128:593-607

24 Andrews PLR, Grundy D, Scratcherd T. Vagal afferent discharge from mechanoreceptors in different regions of the ferret stomach. J Physiol 1980;298:513-24.

25 Blackshaw L, Grundy D, Scratchered T. Vagal afferent discharge from gastric mechanoreceptors during contraction and relaxation of the ferret corpus. J Auton Nerv Syst 1987; 18:19-24.

26 Straathof JWA, van Veen MM, Masclee AAM. Provocation of transient lower esophageal sphincter relaxations during continuous gastric distension. Scand J Gastroenterol 2002;37:1140-3.

27 Scheffer RCH, Akkermans LMA, Bais JE, et al. Elicitation of transient lower oesophageal sphincter relaxations in response to gastric distension and meal ingestion. Neurogastroenterol Motil 2002;14:647-55.

28 Chang HY, Pandolfino JE, Shi G, et al. The effect of glucagon-induced gastric relaxation on TLOSR frequency. Neurogastroenterol Motil 2003;15:3-8.

29 Penagini R, Carmagnola S, Cantù $\mathrm{P}$, et al. Mechanoreceptors of the proximal stomach: role in triggering transient lower esophageal sphincter relaxation. Gastroenterology 2004;126:49-56

30 Stewart JJ, Weisbrodt NW, Burks TH. Central and peripheral actions of morphine on intestinal transit. J Pharmacol Exp Ther 1978;205:547-55.

31 Fioramonti J, Fargeas MJ, Bueno L. Reversal of the effects of centrallyadministered morphine on colonic motility in dogs by the benzodiazepine receptor antagonist RO 15-1788. Life Sci 1987;41:1449-55.

32 Allocca M, Mangano M, Colombo $P$, et al. Effect of loperamide on gastrooesophageal reflux. Scand J Gastroenterol 2003;38:343-6.

33 Piessevaux H, Tack J, Wilmer A, et al. Perception of changes in wall tension of the proximal stomach in humans. Gut 2001;49:203-8.

34 Bruley Des Varannes S, Parys V, Ropert A, et al. Erythromycin enhances fasting and postprandial proximal gastric tone in humans. Gastroenterology 1995; 109:32-9.

35 Mittal RK, Chiareli C, Liu J, et al. Atropine inhibits gastric distension and pharyngeal receptor mediated lower oesophageal sphincter relaxation. Gut 1997;41:285-90

36 Hirsch DP, Tiel-Van Buul MM, Tytgat GNJ, et al. Effect of L-NMMA on postprandial transient lower esophageal sphincter relaxations in healthy volunteers. Dig Dis Sci 2000:45:2069-75.

37 Zerbib F, Bruley Des Varannes S, Scarpignato C, et al. Endogenous cholecystokinin in postprandial lower esophageal sphincter function and fundic tone in humans. Am J Physiol 1998;275:G1266-73. 